\title{
Skin tests in adverse reactions to Pfizer-BioNTech SARS-CoV-2 vaccine: limits of intradermal testing
}

\author{
Leonardo Bianchi ${ }^{1}$, Filippo Biondi ${ }^{1}$, Katharina Hansel $^{2}$, Nicola Murgia ${ }^{3}$, Marta \\ Tramontana $^{2}$, and Luca Stingeni ${ }^{4}$ \\ ${ }^{1}$ Section of Dermatology \\ ${ }^{2}$ Dermatology Section \\ ${ }^{3}$ University of Perugia \\ ${ }^{4}$ Section of Clinical, Allergological and Venereological Dermatology
}

February 25, 2021

Article type: letter to the editor

Skin tests in adverse reactions to Pfizer-BioNTech SARS-CoV-2 vaccine: limits of intradermal testing

Running title: limits of intradermal test with SARS-CoV-2 vaccine

Authors: Leonardo Bianchi ${ }^{1}$, Filippo Biondi ${ }^{1}$, Katharina Hansel ${ }^{1}$, Nicola Murgia ${ }^{2}$, Marta Tramontana ${ }^{1}$, Luca Stingeni ${ }^{1}$

${ }^{1}$ Section of Dermatology, Department of Medicine and Surgery, University of Perugia, Italy

2 Section of Occupational Medicine, Respiratory Diseases and Toxicology, Department of Medicine and Surgery, University of Perugia, Italy

\section{Corresponding author:}

Corresponding author: Leonardo Bianchi, Section of Dermatology, Department of Medicine and Surgery, University of Perugia, Italy. E-mail: leonardo.bianchi@unipg.it

Keywords: SARS-CoV-2 vaccine; adverse drug reaction; skin test; intradermal test

Word count: 593

Number of references: 7

Number of tables: 1

Number of figures: 1

Funding sources: None

Conflict of interest: All authors have no interests to report

Patients consent statement: All patients and controls give their consent to the skin test and to the data publication

The article has not been previously published and is not currently submitted elsewhere

To the Editor, 
Vaccination seems the most effective public health tools to contrast the spreading of Coronavirus disease-19 (COVID-19) pandemic. To date, the European Medicines Agency (EMA) authorized three anti SARS-CoV-2 vaccines. The Pfizer-BioNTech and the Moderna vaccines contain messenger RNA (mRNA) encapsulated in lipid nanoparticles, which encodes the SARS-CoV-2 viral spike (S) protein, inducing both antibody and cell-mediated responses. The AstraZeneca vaccine is based on a viral vector that uses a modified version of the chimpanzee adenovirus to provide instructions for synthesizing SARS-CoV-2 protein S. The vaccine series consists of two doses administered intramuscularly (Pfizer-BioNTech: 21 days apart; Moderna: 28 days apart; AstraZeneca: 28-84 days apart).

During clinical approval studies and early post-marketing phases, mucous-cutaneous adverse reactions have been rarely observed. Among hypersensitivity reactions, immediate reactions (anaphylaxis, urticariaangioedema syndrome) were more frequently observed than delayed reactions (maculo-papular eruptions). 1,2

The anti SARS-CoV-2 vaccines contain excipients with known sensitizing potential: Pfizer-BioNTech vaccine contains polyethylene glycol-2000, Moderna vaccine polyethylene glycol-2000 and tromethamine, and AstraZeneca vaccine polysorbate $80 .^{3}$

Considering this, before receiving anti-SARS-CoV-2 vaccination, an adequate medical history is mandatory to detect possible risk factors and, consequently, to minimize the incidence of adverse reactions. Furthermore, it is recommended to administer the vaccine by trained healthcare personnel in adequate medical settings in presence of emergency drugs and an observation period. ${ }^{3,4}$

In General Hospital of Perugia and in Local Health Unit 1, Umbria Region, Italy, 5574 healthcare professional received the first dose of Pfizer-BioNTech vaccine. Six subjects (0.11\%) developed mucous-cutaneous adverse reactions, summarized in Table 1.

These patients underwent an allergologic workup with Pfizer-BioNTech vaccine as suggested by EAACI ${ }^{4}$ and German allergy centers. ${ }^{5}$ In absence of standardized methodology for this vaccine testing, we referred to Italian $^{6}$ and EAACI recommendations. ${ }^{7}$ Unusable vaccine residues, regain from the vaccine campaign, were used under sterile conditions. Skin prick test (SPT) with neat vaccine (reading: 20 mins), and intradermal test (IDT) vaccine dilution 1/100 (readings: 20 mins, $24 \mathrm{hrs)} \mathrm{were} \mathrm{performed.} \mathrm{SPT} \mathrm{resulted} \mathrm{always} \mathrm{negative,}$ but IDT induced, 12 hours after, an erythematosus, oedematous, and infiltrated asymptomatic reaction in all patients. A 1/1000 dilution test induced the same reaction in all patients (Figure 1A). The IDT reactions persisted for 2 days.

In order to verify these reactions, IDT with $1 / 1000$ and $1 / 100$ Pfizer-BioNTech vaccine dilution were performed in 6 healthcare volunteers who had received the 2 doses of Pfizer-BioNTech vaccine, in 6 healthcare volunteers who had received at least 2 weeks before only the first dose of Pfizer-BioNTech vaccine, and in 6 volunteers who did not receive Pfizer-BioNTech vaccine. All the 18 volunteers did not refer previous allergy to vaccines or drugs containing polyethylene glycols. IDT induced the same reaction 12 hours after in the 12 vaccinated volunteers (Figure 1B), while resulted negative in the 6 not-vaccinated volunteers (Figure 1C). All patients and controls have provided an informed consent to perform these skin tests.

Even if the morphology of the IDT reactions could suggest a type IVa immune reaction, we hypothesized that IDT reactions observed in patients and vaccinated volunteers could be a non-allergic reaction to SARS-CoV-2 viral S protein or to vaccine components.

It is impossible to draw conclusions about the utility of SPT to investigate Pfizer-BioNTech vaccine adverse reactions because of low number of subjects tested, but IDT results allow us to advice against IDT with this vaccine for the high risk of false positive reactions due to non-allergic immune stimulation.

Further studies are needed to investigate the utility of PT and SPT to investigate Pfizer-BioNTech vaccine allergy, and to better clarify the pathomechanism of the reactions observed to IDT.

\section{References}


Shimabukuro T, Nair N. Allergic Reactions Including Anaphylaxis After Receipt of the First Dose of PfizerBioNTech COVID-19 Vaccine.JAMA . 2021 Jan 21. doi: 10.1001/jama.2021.0600. Epub ahead of print. PMID: 33475702 .

Center for Disease Control and Prevention. Allergic Reactions Including Anaphylaxis After

Receipt of the First Dose of Pfizer-BioNTech COVID-19 Vaccine - United States, December 14-23, 2020. https://www.cdc.gov/mmwr/volumes/70/wr/mm7002e1.htm Accessed 17.02.2021.

1. Caballero ML, Quirce S. Excipients as potential agents of anaphylaxis in vaccines: analyzing the formulations of the current authorized COVID-19 vaccines. J Investig Allergol Clin Immunol. 2021 Jan 12:0. doi: 10.18176/jiaci.0667. Epub ahead of print. PMID: 33433387.

2. Sokolowska M, Eiwegger T, Ollert M, et al. EAACI statement on the diagnosis, management and prevention of severe allergic reactions to COVID-19 vaccines. Allergy . 2021 Jan 16. doi: 10.1111/all.14739. Epub ahead of print. PMID: 33452689.

3. Worm M, Bauer A, Wedi B, et al. Practical recommendations for the allergological risk assessment of the COVID-19 vaccination - a harmonized statement of allergy centers in Germany. Allergol Select. 2021 Jan 26;5:72-76. doi: 10.5414/ALX02225E. PMID: 33521511; PMCID: PMC7841415.

4. Stingeni L, Bianchi L, Tramontana M, et al. Skin tests in the diagnosis of adverse drug reactions. $G$ Ital Dermatol Venereol.2020;155(5):602-621.

5. Brockow K, Garvey LH, Aberer W, et al. Skin test concentrations for systemically administered drugs - an ENDA/EAACI Drug Allergy Interest Group position paper. Allergy. 2013;68(6):702-712.

TABLE 1 Patients characteristic and adverse mucous-cutaneous reactions in 6 patients after the first dose of Pfizer-BioNTech vaccine.

\begin{tabular}{|c|c|c|c|c|c|c|}
\hline & Patient 1 & Patient 2 & Patient 3 & Patient 4 & Patient 5 & Patient 6 \\
\hline Gender & Female & Female & Male & Female & Female & Female \\
\hline Age & 24 & 31 & 28 & 58 & 44 & 54 \\
\hline $\begin{array}{l}\text { Personal } \\
\text { atopy }\end{array}$ & $\begin{array}{l}\text { Allergic } \\
\text { rhinitis }\end{array}$ & $\begin{array}{l}\text { Allergic } \\
\text { rhinitis }\end{array}$ & $\begin{array}{l}\text { Allergic } \\
\text { rhinitis }\end{array}$ & $\begin{array}{l}\text { Allergic } \\
\text { rhinitis and } \\
\text { asthma }\end{array}$ & $\begin{array}{l}\text { Allergic } \\
\text { rhinitis }\end{array}$ & $\begin{array}{l}\text { Allergic } \\
\text { rhinitis, } \\
\text { atopic } \\
\text { dermatitis }\end{array}$ \\
\hline $\begin{array}{l}\text { Allergy } \\
\text { history }\end{array}$ & - & - & - & - & - & $\begin{array}{l}\text { Contact } \\
\text { allergy } \\
\text { (nichel } \\
\text { sulphate, } \\
\text { fragrances) }\end{array}$ \\
\hline $\begin{array}{l}\text { Type of } \\
\text { reaction }\end{array}$ & $\begin{array}{l}\text { Acute } \\
\text { urticaria }\end{array}$ & $\begin{array}{l}\text { Angioedema } \\
\text { (tongue, } \\
\text { gums) }\end{array}$ & $\begin{array}{l}\text { Acute } \\
\text { urticaria }\end{array}$ & $\begin{array}{l}\text { Flushing of } \\
\text { the face }\end{array}$ & $\begin{array}{l}\text { Flushing of } \\
\text { the face }\end{array}$ & $\begin{array}{l}\text { Angioedema } \\
\text { (tongue, lips) }\end{array}$ \\
\hline $\begin{array}{l}\text { Time of } \\
\text { onset }\end{array}$ & 5 mins & $24 \mathrm{hrs}$ & 5 mins & 30 mins & 20 mins & 10 mins \\
\hline Treatment & $\begin{array}{l}\text { betametasone } \\
\text { sodium } \\
\text { phosphate } \\
(\mathrm{IV})\end{array}$ & - & - & - & - & - \\
\hline
\end{tabular}

FIGURE 1 Intradermal test (IDT) with Pfizer-BioNTech vaccine. Erythematosus, oedematous, and infiltrated reaction in 2 healthcare volunteers who had received the two doses (A) and only the first dose (B) of Pfizer-BioNTech vaccine. Negative IDT in a not-vaccinated volunteer (C). 


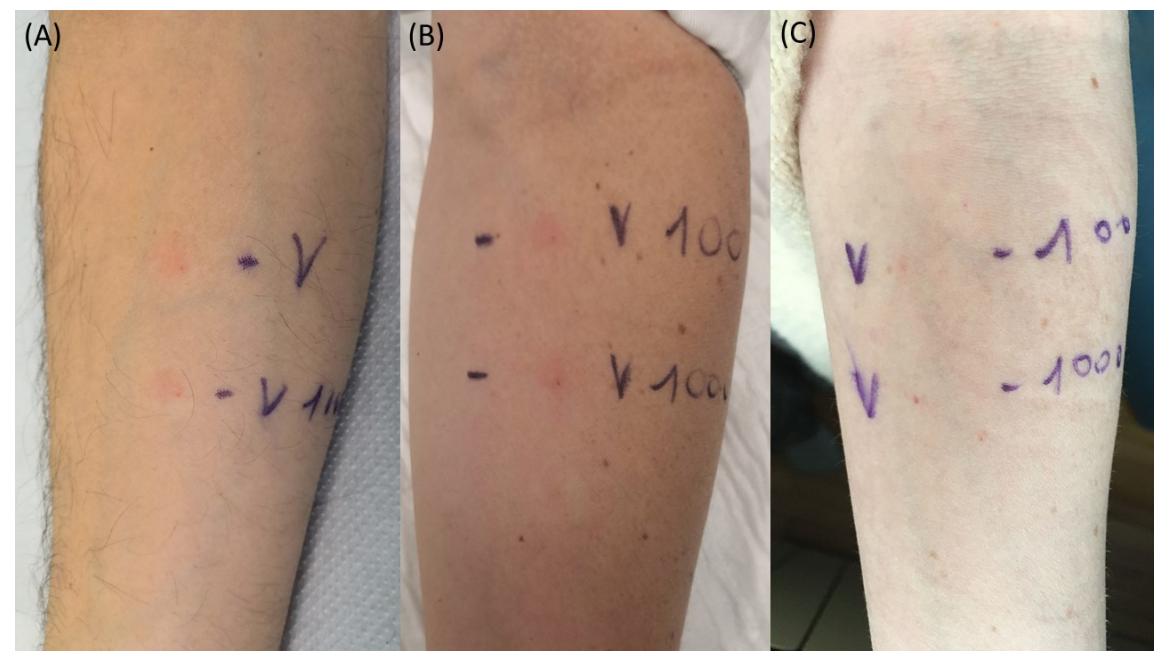

